Published in final edited form as:

Nat Biotechnol. 2019 September 01; 37(9): 1024-1033. doi:10.1038/s41587-019-0244-6.

\title{
Emerging technologies for improved deep brain stimulation
}

\author{
Hayriye Cagnan ${ }^{1,2,{ }^{*}}$, Timothy Denison ${ }^{1,2,3}$, Cameron McIntyre ${ }^{4}$, Peter Brown ${ }^{1,2}$ \\ ${ }^{1}$ MRC Brain Network Dynamics Unit, University of Oxford, Oxford, UK \\ ${ }^{2}$ Nuffield Department of Clinical Neurosciences, University of Oxford, Oxford, UK \\ ${ }^{3}$ Department of Engineering Sciences, University of Oxford, Oxford, UK \\ ${ }^{4}$ School of Medicine, Case Western Reserve University, Cleveland, OH, USA
}

\begin{abstract}
Deep brain stimulation (DBS) is an effective treatment for common movement disorders and has been used to modulate neural activity through delivery of electrical stimulation to key brain structures. The long-term efficacy of stimulation in treating disorders, such as Parkinson's disease and essential tremor, has encouraged its application to a wide range of neurological and psychiatric conditions. Nevertheless, adoption of DBS remains limited, even in Parkinson's disease. Recent failed clinical trials of DBS in major depression, and modest treatment outcomes in dementia and epilepsy, are spurring further development. These improvements focus on interaction with disease circuits through complementary, spatially and temporally specific approaches. Spatial specificity is promoted by the use of segmented electrodes and field steering, and temporal specificity involves the delivery of patterned stimulation, mostly controlled through disease-related feedback. Underpinning these developments are new insights into brain structurefunction relationships and aberrant circuit dynamics, including new methods with which to assess and refine the clinical effects of stimulation.
\end{abstract}

Deep brain stimulation (DBS) is an effective treatment strategy for a wide range of neurological conditions, such as Parkinson's disease ${ }^{1-4}$, essential tremor ${ }^{5,6}$, and dystonia $^{7-10}$. Prior expertise gained from surgical ablation strongly influenced the clinical use of DBS-in particular, the choice of brain regions targeted for stimulation ${ }^{11,12}$. Empirically chosen stimulation parameters (e.g., a 130-180 Hz stimulation frequency, a 60$90 \mu$ s pulse width, and $1-4 \mathrm{~V}$ stimulation intensity $)^{6}$ induce similar clinical outcomes to those observed with surgical ablation. Long-term efficacy of applying high-frequency stimulation to certain brain regions ${ }^{5}$, together with the reversible nature of DBS and the

\footnotetext{
*Correspondence should be addressed to H.C. hayriye.cagnan@ndcn.ox.ac.uk. Competing interests

C.M. is a shareholder in Surgical Information Sciences, Hologram Consultants, Cortics, Autonomic Technologies, Cardionomic and Enspire DBS, as well as a paid consultant to Boston Scientific Neuromodulation. C.M. has intellectual property directly related to the areas we discuss and receives royalties from Neuros Medical, Boston Scientific, Hologram Consultants and Qr8 Health. T.D. is a shareholder in Medtronic, is a consultant for Inspire Medical and Cortec Neurotechnologies, is an advisor for Nia therapeutics, and has intellectual property directly related to the areas we discuss. P.B. has intellectual property directly related to the areas we discuss. H.C. has intellectual property directly related to the areas we discuss.

Reprints and permissions information is available at www.nature.com/reprints.

Publisher's note: Springer Nature remains neutral with regard to jurisdictional claims in published maps and institutional affiliations.
} 
possibility of reducing the amount of drugs administered to patients with Parkinson's disease ${ }^{13}$, has helped adoption of this electroceutical treatment, which can reduce symptoms by an average of 40\% 3-4 years after surgery ${ }^{14}$. Even in Parkinson's disease, however, as few as $2 \%$ of patients undergo DBS ${ }^{15}$, potentially reflecting the invasive nature of the intervention, the high cost of treatment and limited access to, or fear of, surgery.

A critical aspect of DBS efficacy is patient selection and the choice of the appropriate target location based on patient's symptom profile, age and cognitive status ${ }^{13,16-18}$. These choices heavily rely on the expertise of the surgical team and vary from center to center. Surgical complications include hemorrhage, infection, skin erosion and hardware-related complications, such as stimulator failure and electrode fracture ${ }^{16,19}$. In addition, an important postoperative limitation of DBS is stimulation-induced side effects caused by electrical activation of the surrounding brain tissue. Up to 50\% of implanted patients can experience stimulation-induced side effects, albeit not severe ones in most cases ${ }^{14}$. Prevalence of side effects strongly depends on the target nucleus and the anatomy and functionality of the surrounding tissue ${ }^{14}$. Emerging technologies such as segmented electrodes and closed-loop DBS aim to minimize these side effects.

In this Review, we provide an overview of the mechanism of DBS within the context of movement disorders and assess application of DBS for treatment of various neurological and psychiatric conditions. We discuss recent technological advancements that could improve stimulation location and timing, highlight types of signals that could be used as a biomarker, and provide an overview of how these biomarkers could be decoded to deliver closed-loop stimulation. We review studies that provide alternative stimulation strategies to state-of-theart high-frequency DBS and explore different control policies. We highlight important considerations for therapy safety as the field moves toward treatments that continuously adapt stimulation parameters according to a disease biomarker. Finally, we review some of the upcoming technologies that could shape the neuromodulation field.

\section{DBS mechanism and movement disorders}

The similarities between the outcome observed with applying high-frequency stimulation and lesioning the same brain region led to the initial hypothesis that DBS inhibited neural activity and reduced the output of the target nucleus. This was supported by experimental evidence that showed a reduction in neural activity at the site of stimulation, potentially through the activation of inhibitory projections to the target region ${ }^{20-23}$. Hashimoto et al., by contrast, reported that downstream neural activity increased during high-frequency stimulation of one of the most common target nuclei used for the management of Parkinson's disease symptoms: the subthalamic nucleus ${ }^{24}$. This observation was corroborated by other studies that concluded that downstream neural activity was either upregulated or downregulated depending on whether the projection from the target nucleus to the downstream nucleus was excitatory or inhibitory, respectively ${ }^{25-29}$. Further research has demonstrated that upstream targets could similarly be affected by antidromic conduction $^{30,31}$. Taken together, this body of work raised a paradox regarding the mechanism of DBS. An influential theoretical model capturing the effect of high-frequency stimulation on thalamic neurons suggested that stimulation could directly activate axons 
traversing or adjacent to nuclei while inhibiting activity at the somata, reconciling the experimental evidence on modulation of upstream and downstream activity in the presence of a reduction in neural activity at the site of stimulation ${ }^{32}$ (Fig. 1).

The current consensus regarding the mechanism of DBS is that high-frequency stimulation modulates neural activity at afferent and efferent brain regions $24,33,34$ to restore function ${ }^{35}$. For disorders characterized as oscillopathies, where patients' symptom severity is correlated with excessive rhythmic neural activity at the DBS target region and projection targets (for example, Parkinson's disease ${ }^{36}$, essential tremor ${ }^{37}$ and dystonia ${ }^{38}$ ), high-frequency electrical stimulation has been shown to suppress rhythmic neural activity and concurrently alleviate patients' symptoms ${ }^{38,39}$. A similar mechanism has been recently observed during stimulation of the anterior nucleus of the thalamus for the treatment of refractory focal seizures: stimulation was effective in desynchronizing downstream hippocampal activity only when it was applied at high frequencies ${ }^{40}$. This stimulation effect has been linked to a suppression of epileptic activity, highlighting a potential mechanism for stimulation efficacy comparable to those highlighted for other oscillopathies ${ }^{41-43}$. Indeed, evidence is emerging that oscillatory activity may also play a role in psychiatric conditions like obsessivecompulsive disorder ${ }^{44,45}$ and Tourette's syndrome ${ }^{46}$. However, there is nothing to suggest that DBS exclusively acts through the overwriting of pathological oscillatory activities; aberrant, arrhythmic circuit motifs underlying symptoms, although more difficult to detect, may also be overwritten.

\section{Beyond movement disorders}

In recent years, use of DBS has been extended to the treatment of a wide range of neurological and psychiatric conditions, such as Tourette's syndrome ${ }^{18,47}$, obsessivecompulsive disorder48_50, major depression ${ }^{51-53}$ and Alzheimer's disease ${ }^{54,55}$ (Table 1). However, treatment of these disorders remains experimental, with the exception of obsessive-compulsive disorder, which is regulated under a humanitarian exemption. Two clinical trials studying the use of DBS for the treatment of major depression ${ }^{53,56}$ have failed. Pilot results in Alzheimer's disease were similarly limited ${ }^{54}$. For these diseases, several critical aspects of therapy remain unresolved - in particular where, when and how stimulation should be delivered in the light of individual anatomical and pathophysiological differences. Failure to take into account these issues has arguably given rise to inconsistent clinical outcomes for the majority of the aforementioned neuropsychiatric disorders. In the upcoming sections, we review recent technical advances in the neuromodulation field that could enhance therapeutic efficacy and selectivity not only for the existing applications of DBS, but also for future applications to other medication-refractory neurological and psychiatric disorders.

\section{Where to stimulate?}

Stimulation efficacy strongly depends on the target brain region. For instance, in Parkinson's disease, delivering high-frequency DBS to the subthalamic nucleus and local fiber pathways is able to suppress all the cardinal symptoms of the disease: bradykinesia, rigidity and tremor4. In contrast, high-frequency DBS delivered to the ventrolateral thalamus reduces 
tremor severity but is relatively ineffective for the management of bradykinesia and rigidity ${ }^{57}$. Similar considerations apply in the context of epilepsy, where complex network models are beginning to be employed to determine the most effective target location for surgical intervention ${ }^{58,59}$.

Once a target is selected, the accuracy with which it is stimulated is critical so that the volume of tissue activated (VTA) matches, as best as possible, the target structure. Traditionally, this has been achieved first via electrode contact selection and then by manipulations of the amplitude and width of the stimulus pulse $\mathrm{s}^{60-62}$. Electrode design is also a key determinant of the VTA during DBS. To facilitate application of DBS technology to the treatment of various neurological and psychiatric disorders, the design of the electrode should allow a flexible interface when targeting different brain regions, compensating for morphological differences and surgical variance. The traditional cylindrical DBS electrode design uses four cylindrical contacts (for example, $1.27 \mathrm{~mm}$ in diameter and $1.5 \mathrm{~mm}$ in height for the Medtronic 3387/3389 quadripolar DBS electrode). The VTA around the electrode critically depends on the number of contacts used for stimulation; return reference (i.e., monopolar versus bipolar); stimulation parameters, such as amplitude and pulse width; and properties of the tissue surrounding the electrode (i.e., isotropic-homogenous across all orientations-versus anisotropic) ${ }^{63-65}$.

In isotropic media, stimulation delivered using cylindrical DBS electrodes gives rise to a symmetric, omnidirectional VTA around the electrode, and induced side effects can only be reduced by either minimizing the duration and stimulation intensity or changing to bipolar mode. Thus, anisotropic media affect the VTA and, in the case of cylindrical DBS electrodes, affect the symmetry of the field around the electrode. However, for certain disorders, target regions and placements minimizing the stimulation intensity may not be sufficient to reduce stimulation induced side effects. Therefore, in recent years, electrode designs that allow field steering ${ }^{66}$ have taken center stage as an alternative to cylindrical DBS electrodes. The added precision that these electrodes afford can help improve the accuracy of lead interfacing (Fig. 2).

Segmented electrodes allow greater control over the VTA through field steering and independent control of electrode contacts. Current commercial variants achieve directionality by replacing the middle two cylindrical contacts of traditional quadripolar electrodes with three segmented electrodes, increasing the total number of programmable contacts from four to eight and allowing three radial directions of stimulation separated by 120 degrees. These segmented electrodes allow clinicians to modify side-effect thresholds and create a greater margin between symptom suppression and side-effect induction (the therapeutic window) ${ }^{67-73}$. Upcoming technologies, such as thin-film planar arrays, could provide further improvement to spatial specificity of stimulation and recordings acquired from disease circuits ${ }^{74}$, through reduced contact size and increased contact numbers.

However, increased electrode precision comes with trade-offs. The greater flexibility afforded by segmented electrodes and thin planar arrays considerably increases the degrees of freedom allowed in programming. This flexibility increases the burden on the clinical team ${ }^{72}$ because optimal stimulation contact and parameter selection mostly rely on a process 
of trial and error. Therefore, automated or support tools for assisting clinicians in determining optimal stimulation parameters are sorely needed. For example, it has recently been shown that the use of a disease biomarker, such as heightened rhythmic neural activity, can reduce the amount of time needed for programming segmented electrodes for the treatment of Parkinson's disease ${ }^{71,72}$. Evoked potentials might also be useful in this regard $^{75}$. Strategies that consider electrode location and anatomical landmarks in conjunction with individualized diffusion tensor imaging could provide additional information needed to reduce the degrees of freedom associated with programming DBS electrodes $^{76-78}$.

\section{How and when to stimulate}

In recent years, the traditional practice of continuously stimulating the brain using static stimulation parameters has shifted to the use of disease biomarkers and patient's state (for example, awake or asleep) or actions to determine how much and when to stimulate. The main motivation behind closed-loop stimulation is minimization of treatment side effects by providing only the necessary stimulation required within a certain time window, as determined from a guiding biomarker. This in turn limits any unwanted direct stimulation of nearby fiber tracts, such as those in the internal capsule responsible for many aspects of the dysarthria that may complicate stimulation of the subthalamic nucleus ${ }^{79}$. It has also been suggested that temporal patterning of stimulation could spare residual local physiological neural processing, as in the case of physiological bursts of beta activity in the subthalamic nucleus related to decision conflict, where DBS-driven suppression leads to motor impulsivity ${ }^{80}$. Similarly, adverse effects of DBS on sleep might decrease during responsive stimulation of the anterior nucleus of the thalamus for treatment of epilepsy ${ }^{81}$. Closed-loop stimulation could be essential not only to reverse direct side effects of stimulation, but also to minimize adverse effects due to combined pharmacological treatment, as has been explored in the context of dyskinesias observed in Parkinson's disease due to dopaminergic medication $^{82,83}$.

Closed-loop stimulation is also being investigated for the treatment of neuropsychiatric disorders, such as obsessive-compulsive disorder and Tourette's syndrome ${ }^{50,84}$, in Tourette's syndrome, a case report of closed-loop stimulation has already been published ${ }^{85}$. The viability of these approaches will strongly depend on identification of reliable disease biomarkers that reflect patients' symptom severity and change with treatment ${ }^{46,49}$. Critically, though, closed-loop DBS has only hitherto been trialled over periods of time measured in hours, with the exception of closed-loop stimulation for pain and epilepsy management (Box 1). Thus, it remains to be seen whether the efficacy and side-effect profile of closed-loop DBS is maintained sufficiently to warrant chronic use for treatment of movement disorders and neuropsychiatric conditions. In this regard, the recent development of bidirectional implantable devices, such as the Responsive Neurostimulation system (RNS) manufactured by Neuropace ${ }^{86}$ or the Activa $\mathrm{PC}+\mathrm{S}$ manufactured by Medtronic ${ }^{87}$, is noteworthy. In particular, Activa $\mathrm{PC}+\mathrm{S}$ can serve the dual purpose of interrogating diseases for biomarkers useful for closed-loop DBS and piloting such therapy over long periods while retaining the option of defaulting to conventional stimulation. 


\section{Biomarkers for closing the loop}

Various classes of signals have been used to determine when and how much to stimulate, including pathological neural activity ${ }^{79,82,88-90}$ and peripheral measurements ${ }^{91,92}$.

Biomarkers need not necessarily be directly related to disease mechanisms, but should correlate with the severity of disease symptoms ${ }^{36,93-95}$ and track the response to therapeutic interventions $39,46,93,95,96$. The relevant signals may be relatively unprocessed or subject to several processing steps to extract the information of interest, with or without the aid of machine learning. Processing commonly involves spectral analysis. As will be seen below, this serves to focus on a particular pathological oscillation, but in the future, control is more likely to be based on combinations of spectral and other features ${ }^{97}$, some with different temporal resolutions, such as phase-amplitude coupling and coherence between brain sites.

Closed-loop DBS strategies have thus far mainly focused on the treatment of common movement disorders, such as Parkinson's disease and essential tremor (Fig. 3). In these indications, two types of neural control signal have been exploited to determine when and how much to stimulate. First, the instantaneous power of rhythmic neural activity in the beta band $(20 \mathrm{~Hz})$ can be tracked in the form of the local field potential at the site of stimulation ${ }^{79,88-90}$. This approach has the advantage of sensing and stimulating via the same electrode and therefore minimizing surgical instrumentation needed to implement closedloop stimulation. Recordings direct from the stimulation electrode may also allow feedback through evoked activity ${ }^{75}$. Second, the instantaneous power of rhythmic neural activity can be tracked in the motor cortex. In the latter case, studies have focused on gamma activity $(\sim 75 \mathrm{~Hz})$ in the control of dyskinesias ${ }^{82}$ or on movement-related modulation of beta activity in the control of tremor ${ }^{98}$. This approach limits contamination of the feedback signal by stimulus artifact and leverages the improved signal-to-noise ratio of cortical recordings.

A different approach is the use of peripheral sensors for feedback, which also circumvents stimulus artifact and may prove useful for gait disturbance and tremor ${ }^{91,92,99-102}$. However, with this approach additional constraints need to be addressed, such as the energy expenditure associated with wireless communication between the peripheral sensor and the implanted stimulator, the security of wireless communication and the fact that information from peripheral sensors follows the development of symptoms and is therefore not predictive. Patient compliance in the wearing of peripheral sensors is another important consideration.

\section{Decoding biomarkers for closing the loop}

Applications of closed-loop DBS have mainly focused on the use of specific signal features, such as neural activity in the beta or gamma frequency bands, to control stimulation timing for a range of movement disorders. However, the exact mapping between neural activity and symptom severity remains unknown for most neuropsychiatric disorders, which necessitates the use of alternative techniques. Real-time decoding strategies could be employed to identify signal features that could be used as a proxy for the patient's symptom severity or behavioral state. Features extracted from thalamic field potentials have been used to decode onset of tremor and tremor-triggering voluntary movement in a group of patients with 
essential tremor ${ }^{103}$, while subthalamic field potentials from patients with Parkinson's disease have been successfully used to determine the amount of muscular force exerted ${ }^{104}$. The feature space could be different frequency bands obtained from electrophysiological recordings, derived using techniques such as wavelet transforms or fast Fourier transforms ${ }^{103,104}$. Important considerations for real-time implementation of such strategies are energy expenditure and processing cost of decoding algorithms. Similarly, the timescales over which signal features evolve can be a complicating factor, especially when features of interest fluctuate over vastly different time scales (for example, seconds to days).

Potential solutions for such scenarios could be (i) to use a combination of cloud computing and real-time processing utilizing implanted electronics ${ }^{105}$ or (ii) to process signal features that are fluctuating at a slower rate using a lower sampling rate than the ones evolving at a much faster rate. Although previous examples of decoding relied on recordings from single brain regions, this may not be sufficient for most neuropsychiatric applications. For these applications, the feature space could include changes in coupling across multiple sites ${ }^{106-108}$, providing more insight into network properties that could be leveraged to further adjust stimulation parameters, particularly when treating disorders driven by complex network architectures. Coupling across different sites could be derived from either field potentials ${ }^{106,107}$ or field potential and single-unit activity ${ }^{108}$ and could be based on fluctuations in activity timing (i.e., phase coupling) and/or strength (i.e., amplitude coupling). It should be noted that while the utility of single-unit activity has been demonstrated in animal experiments ${ }^{109}$, state-of-the-art chronically implanted devices for the treatment of neuropsychiatric disorders only provide access to field potentials.

Another important consideration for decoding neural activity is the resolution of symptom severity or behavioral measures. Although symptom severity in movement disorders can be derived in real time using either peripheral sensors (for example, ones that measure tremor severity) or neural activities with a previously established relationship with symptoms, this is not feasible when, for instance, decoding patients' mood. Sparsity of behavioral measures coupled with high dimensionality of feature space have been elegantly addressed in a recent study by Sani et al., wherein the authors propose that (i) restricting the number of model parameters, (ii) limiting the number of brain regions used for decoding mood, and (iii) using a low-dimensional state space could enable decoding of mood variations while minimizing problems such as overfitting ${ }^{97}$.

\section{Getting away from high-frequency stimulation}

Several theoretical models suggest that moving away from high-frequency stimulation to pathology- and brain-region-specific stimulation could improve the therapeutic outcome further not only by inducing long-lasting plastic changes but also by limiting the amount of energy delivered and thereby side effects. Coordinated reset is a theoretical concept put forward to desynchronize a population of neurons by delivering patterns of short pulses in a coordinated fashion across different electrode contacts ${ }^{110}$. Efficacy of coordinated reset together with long-lasting effects of this stimulation strategy have been experimentally shown in both MPTP (1-methyl-4-phenyl-1,2,3,6-tetrahydropyridine)-treated monkeys and a 
group of patients with Parkinson's disease, although in the latter case no control group was included $^{111,112}$.

Another influential theoretical model focuses on tailoring the stimulation pattern according to the temporal properties of the pathological neural activity in a closed-loop fashion, under the hypothesis that stimulation at a certain phase of neural activity can disrupt synchrony ${ }^{113-115}$. This stimulation strategy, referred to as phase-specific DBS, has been shown to be effective in acutely suppressing tremor in a group of patients with essential tremor, despite using $\sim 40 \%$ of the total electrical energy delivered per unit time associated with conventional high-frequency $\mathrm{DBS}^{91}$. Like coordinated reset, this stimulation approach has the potential to minimize DBS-induced side effects by reducing the amount of energy delivered to the brain.

\section{Control policies need not be fixed}

Consideration of patient behavior, such as sleep, walking or decision making, could also further aid in determining optimal stimulation patterns. In recent electrophysiological studies, only high-frequency stimulation that was delivered at a certain period of the decision-making process impaired patients' behavior, suggesting that adapting stimulation timing according to patient behavior could limit such adverse effects ${ }^{80,116,117}$.

In a similar vein, alternating stimulation patterns between hemispheres according to patients' walking pattern could potentially improve gait by reinforcing the physiological modulation of beta activity with stepping ${ }^{118}$. The timing of stimulation may also prove important during sleep, where the available evidence already suggests that even conventional high-frequency stimulation can improve or worsen patients' sleep quality according to stimulation site 81,119 . In sum, these observations highlight a potential new avenue for stimulation control: tailoring stimulation not only according to pathology and its circuit manifestations, but also according to the everyday actions and behaviors of patients.

\section{Safety and future-proofing}

As we transition from the laboratory to clinical use of advanced DBS technologies, care should be taken regarding patient safety and sustained stimulation efficacy ${ }^{120}$. Many of these considerations are captured in the ISO guidance 60601-1-10, essential requirements for physiologic control systems. One example for both segmented leads and adaptive algorithms is the setting of safe boundaries for stimulation. For field steering, controls should be used to ensure that a safe charge density is applied. For adaptive algorithms, upper and lower boundaries for stimulation intensity should be fixed on the basis of clinical assessment, and any algorithm's stimulation updates limited to this predetermined safe zone of operation ${ }^{120}$.

Another safety procedure is to define a fallback mode. For directional leads, the ability to revert to ring mode (the most common setting) and provide 'classical' stimulation is an important risk-mitigation approach. For adaptive systems, an open-loop stimulation at predetermined parameters should be made readily available to the patient to ensure sustained stimulation efficacy in case of an unforeseen limitation of the closed-loop approach. These 
concepts have been demonstrated in several investigational studies for Parkinson's disease and essential tremor ${ }^{82,98}$.

\section{The future}

DBS is undergoing a renaissance as it evolves from a 'reversible lesion' to a targeted prosthesis that dynamically and accurately restores brain function. For accuracy, spatial selectivity is enhanced through higher resolution electrodes; for dynamics, we are on the verge of a paradigm shift away from monotonic high-frequency stimulation toward temporal patterning informed by dynamics in neural circuits and symptoms. These developments push us ever closer to the goal of individualized therapy that tracks clinical state. However, more sophisticated control requires a greater understanding of pathophysiology to allow the development of useful biomarkers and, where necessary, biomarker combinations to dictate stimulation. Similarly, control algorithms should mature while maintaining tractability. Most of all, at every point in the development journey, we must remain open to alternative noninvasive $^{121,122}$ or minimally invasive electrical and other interventions ${ }^{123,124}$, when and if these compete in terms of efficacy.

In the near future, technology trends in the broader landscape, such as the 'Internet of Things', will further help support the adoption of new technologies. These trends include both automation and information processing, as well as device miniaturization. For example, the use of rechargeable systems and secure telemetry allows continuous wireless upload of data with marginal impact on device longevity. The increased data uploads will allow more continuous patient assessments and more complex control on multiple timescales using offthe-body local and distributed cloud computing systems. At the same time, such a system lends itself to integration of data from peripheral sensors, the output of which may be fed into machine-learning methods to provide summaries that aid decision-making and prevent clinicians from being overloaded with too much information. A prototype for this style of control has been recently published in a canine model of epilepsy, in preparation for investigational studies in human ${ }^{105}$. Modern circuit technology also allows firmware to be rewritten in the device. Firmware upgrades 'future-proof' the implant and allow patients to benefit from enhancements in adaptive algorithms ${ }^{82,125}$. The ability to update algorithms is especially important for rechargeable systems, which might last more than a decade.

All of these methods require care in security and risk management to ensure patient safety and minimize the threat of malicious hacks. Guidance from regulators is helping to inform more robust device architectures ${ }^{126}$. In addition, the continued focus on miniaturization will drive innovations in device design and surgical techniques. In the past few years, cardiac pacemakers without leads have been developed that can be implanted through endovascular techniques. This new design minimizes complication rates while maintaining basic therapy functionality ${ }^{127}$. Similar techniques are being explored for neuromodulation, whereby electrodes implanted through less invasive vascular routes might provide access to the nervous system without the necessity of cranial burr holes and tissue-disrupting lead insertion ${ }^{128}$. All of these existing technology trends are expected to cross-pollinate with brain stimulation and further advance the field. These advancements could potentially reduce the invasive nature of DBS surgery and minimize the risk of infection in hospital settings. 
In the longer term, it is likely that brain stimulation therapies will be further disrupted by advancing technology, much as DBS originally disrupted ablation procedures. New mechanisms to actuate the nervous system with optogenetics or other cell-specific targeting approaches could greatly refine the ability to modulate and control neural circuits. Although technical limitations on transfection efficiency remain, improvements in opsin quality ${ }^{129}$ and the adoption of gene therapies in clinical trials ${ }^{130}$ are removing some barriers to translation ${ }^{131}$. At the other extreme, minimally invasive methods such as transcranial ultrasound are enabling 'non-invasive' ablation of neural circuits, such as those in the thalamus for tremor ${ }^{124}$, and the field is now expanding to explore real-time modulation of cortical and subcortical circuits ${ }^{132-134}$. These approaches might one day provide the many of benefits of DBS without the requirement of cranial surgery; the physical implementation of an ambulatory ultrasound system is an active area of technology development. Technology might also provide a means to improve the specificity of an implant, with substantially less invasiveness, using hybrid methods that combine implantable and wearable systems. For example, distributed ultrasound-linked 'neural dust' might provide a means to distribute energy and sensing capability across broad networks with minimal physical impact, enabling a scale of neural interfacing that is hard to replicate with physically tethered leads ${ }^{135,136}$. Hybrid methods might also include access from the periphery ${ }^{137}$.

Laser thermal ablation and radiosurgery provide an ablationbased alternative to DBS, which could be used in combination with magnetic resonance imaging guidance to increase targeting accuracy. Critically, these therapies are more cost effective than DBS without compromising therapy efficacy when unilateral targeting would suffice for controlling disease symptoms ${ }^{138-140}$. The main limitation of all ablation-based alternatives, however, remains laterality of the treatment. The vagal nerve system is currently used for the treatment of epilepsy and is being explored for stroke rehabilitation. As our understanding of interactions between the peripheral and central nervous system increases ${ }^{141,142}$, we expect there to be less of a dichotomy in treatment approaches, which will further motivate distributed neural interfaces.

One final area for consideration is how other cell types might figure into optimizing therapy. The role of glia and astrocytes in neural computation is still ambiguous, but could provide another degree of freedom for modulating neural circuit activity. In sum, the rate of technology development coupled with the unknowns of clinical neuroscience make the future hard to predict, but the large burden of neurological disorders motivates new innovations.

\section{Acknowledgements}

This work was supported by the Medical Research Council UK (MC_UU_12024/1 1188 to P.B. and MR/ R020418/1 to H.C.). T.D. is supported by the Royal Academy of Engineering through a chair in emerging technology. C.M. is supported by NIH R01 NS086100.

\section{References}

1. Obeso JA, et al. Deep-brain stimulation of the subthalamic nucleus or the pars interna of the globus pallidus in Parkinson's disease. N Engl J Med. 2001; 345:956-963. [PubMed: 11575287] 
2. Deuschl G, et al. A randomized trial of deep-brain stimulation for Parkinson's disease. N Engl J Med. 2006; 355:896-908. [PubMed: 16943402]

3. Benabid AL, Chabardes S, Mitrofanis J, Pollak P. Deep brain stimulation of the subthalamic nucleus for the treatment of Parkinson's disease. Lancet Neurol. 2009; 8:67-81. [PubMed: 19081516]

4. Rodriguez-Oroz MC, et al. Bilateral deep brain stimulation in Parkinson's disease: a multicentre study with 4 years follow-up. Brain. 2005; 128:2240-2249. [PubMed: 15975946]

5. Koller WC, Lyons KE, Wilkinson SB, Troster AI, Pahwa R. Long-term safety and efficacy of unilateral deep brain stimulation of the thalamus in essential tremor. Mov Disord. 2001; 16:464 468. [PubMed: 11391740]

6. Benabid AL, et al. Long-term suppression of tremor by chronic stimulation of the ventral intermediate thalamic nucleus. Lancet. 1991; 337:403-406. [PubMed: 1671433]

7. Kupsch A, et al. Pallidal deep-brain stimulation in primary generalized or segmental dystonia. N Engl J Med. 2006; 355:1978-1990. [PubMed: 17093249]

8. Vidailhet M, et al. Bilateral deep-brain stimulation of the globus pallidus in primary generalized dystonia. N Engl J Med. 2005; 352:459-467. [PubMed: 15689584]

9. Kiss ZH. Bilateral pallidal neurostimulation-long-term motor and cognitive effects in primary generalized dystonia. Nat Clin Pract Neurol. 2007; 3:482-483. [PubMed: 17622231]

10. Kiss ZHT, et al. The Canadian multicentre study of deep brain stimulation for cervical dystonia. Brain. 2007; 130:2879-2886. [PubMed: 17905796]

11. Bergman H, Wichmann T, DeLong MR. Reversal of experimental parkinsonism by lesions of the subthalamic nucleus. Science. 1990; 249:1436-1438. [PubMed: 2402638]

12. Jankovic J, Cardoso F, Grossman RG, Hamilton WJ. Outcome after stereotactic thalamotomy for parkinsonian, essential, and other types of tremor. Neurosurgery. 1995; 37:680-686. [PubMed: 8559296]

13. Limousin P, et al. Electrical stimulation of the subthalamic nucleus in advanced Parkinson's disease. N Engl J Med. 1998; 339:1105-1111. [PubMed: 9770557]

14. Volkmann J, et al. Long-term effects of pallidal or subthalamic deep brain stimulation on quality of life in Parkinson's disease. Mov Disord. 2009; 24:1154-1161. [PubMed: 19412954]

15. Kestenbaum M, Ford B, Louis ED. Estimating the proportion of essential tremor and Parkinson's disease patients undergoing deep brain stimulation surgery: five-year data from Columbia University Medical Center (2009-2014). Mov Disord Clin Pract (Hoboken). 2015; 2:384-387. [PubMed: 28845438]

16. Hariz MI. Complications of deep brain stimulation surgery. Mov Disord. 2002; 17(Suppl. 3):S162S166. [PubMed: 11948772]

17. Hariz MI, et al. Bilateral subthalamic nucleus stimulation in a parkinsonian patient with preoperative deficits in speech and cognition: persistent improvement in mobility but increased dependency: a case study. Mov Disord. 2000; 15:136-139. [PubMed: 10634253]

18. Mink JW, et al. Patient selection and assessment recommendations for deep brain stimulation in Tourette syndrome. Mov Disord. 2006; 21:1831-1838. [PubMed: 16991144]

19. Blomstedt P, Hariz MI. Hardware-related complications of deep brain stimulation: a ten year experience. Acta Neurochir (Wien). 2005; 147:1061-1064. [PubMed: 16041470]

20. Benazzouz A, et al. Effect of high-frequency stimulation of the subthalamic nucleus on the neuronal activities of the substantia nigra pars reticulata and ventrolateral nucleus of the thalamus in the rat. Neuroscience. 2000; 99:289-295. [PubMed: 10938434]

21. Dostrovsky JO, et al. Microstimulation-induced inhibition of neuronal firing in human globus pallidus. J Neurophysiol. 2000; 84:570-574. [PubMed: 10899228]

22. Welter M-L. et al. Effects of high-frequency stimulation on subthalamic neuronal activity in parkinsonian patients. Arch Neurol. 2004; 61:89-96. [PubMed: 14732625]

23. Meissner W, et al. Subthalamic high frequency stimulation resets subthalamic firing and reduces abnormal oscillations. Brain. 2005; 128:2372-2382. [PubMed: 16123144]

24. Hashimoto T, Elder CM, Okun MS, Patrick SK, Vitek JL. Stimulation of the subthalamic nucleus changes the firing pattern of pallidal neurons. J Neurosci. 2003; 23:1916-1923. [PubMed: 12629196] 
25. Anderson ME, Postupna N, Ruffo M. Effects of high-frequency stimulation in the internal globus pallidus on the activity of thalamic neurons in the awake monkey. J Neurophysiol. 2003; 89:1150 1160. [PubMed: 12574488]

26. Montgomery EB Jr. Effects of GPi stimulation on human thalamic neuronal activity. Clin Neurophysiol. 2006; 117:2691-2702. [PubMed: 17029953]

27. Vitek JL, Zhang J, Hashimoto T, Russo GS, Baker KB. External pallidal stimulation improves parkinsonian motor signs and modulates neuronal activity throughout the basal ganglia thalamic network. Exp Neurol. 2012; 233:581-586. [PubMed: 22001773]

28. Hershey T, et al. Cortical and subcortical blood flow effects of subthalamic nucleus stimulation in PD. Neurology. 2003; 61:816-821. [PubMed: 14504327]

29. Perlmutter JS, et al. Blood flow responses to deep brain stimulation of thalamus. Neurology. 2002; 58:1388-1394. [PubMed: 12011286]

30. Li S, Arbuthnott GW, Jutras MJ, Goldberg JA, Jaeger D. Resonant antidromic cortical circuit activation as a consequence of high-frequency subthalamic deep-brain stimulation. J Neurophysiol. 2007; 98:3525-3537. [PubMed: 17928554]

31. Miocinovic $\mathrm{S}$, et al. Cortical potentials evoked by subthalamic stimulation demonstrate a short latency hyperdirect pathway in humans. J Neurosci. 2018; 38:9129-9141. [PubMed: 30201770]

32. McIntyre CC, Grill WM, Sherman DL, Thakor NV. Cellular effects of deep brain stimulation: model-based analysis of activation and inhibition. J Neurophysiol. 2004; 91:1457-1469. [PubMed: 14668299]

33. Xu W, Russo GS, Hashimoto T, Zhang J, Vitek JL. Subthalamic nucleus stimulation modulates thalamic neuronal activity. J Neurosci. 2008; 28:11916-11924. [PubMed: 19005057]

34. Johnson MD, Vitek JL, McIntyre CC. Pallidal stimulation that improves parkinsonian motor symptoms also modulates neuronal firing patterns in primary motor cortex in the MPTP-treated monkey. Exp Neurol. 2009; 219:359-362. [PubMed: 19409895]

35. Rubin JE, Terman D. High frequency stimulation of the subthalamic nucleus eliminates pathological thalamic rhythmicity in a computational model. J Comput Neurosci. 2004; 16:211235. [PubMed: 15114047]

36. Kühn AA, et al. Pathological synchronisation in the subthalamic nucleus of patients with Parkinson's disease relates to both bradykinesia and rigidity. Exp Neurol. 2009; 215:380-387. [PubMed: 19070616]

37. Schnitzler A, Münks C, Butz M, Timmermann L, Gross J. Synchronized brain network associated with essential tremor as revealed by magnetoencephalography. Mov Disord. 2009; 24:1629-1635. [PubMed: 19514010]

38. Barow E, et al. Deep brain stimulation suppresses pallidal low frequency activity in patients with phasic dystonic movements. Brain. 2014; 137:3012-3024. [PubMed: 25212852]

39. Eusebio A, et al. Deep brain stimulation can suppress pathological synchronisation in parkinsonian patients. J Neurol Neurosurg Psychiatry jnnp. 2010; 2010

40. Yu T, et al. High-frequency stimulation of anterior nucleus of thalamus desynchronizes epileptic network in humans. Brain. 2018; 141:2631-2643. [PubMed: 29985998]

41. Medeiros D, de C, Moraes MFD. Focus on desynchronization rather than excitability: a new strategy for intraencephalic electrical stimulation. Epilepsy Behav. 2014; 38:32-36. [PubMed: 24472684]

42. Stypulkowski PH, Stanslaski SR, Jensen RM, Denison TJ, Giftakis JE. Brain stimulation for epilepsy-local and remote modulation of network excitability. Brain Stimul. 2014; 7:350-358. [PubMed: 24613614]

43. Kim HY, et al. Modification of electrophysiological activity pattern after anterior thalamic deep brain stimulation for intractable epilepsy: report of 3 cases. J Neurosurg. 2017; 126:2028-2035. [PubMed: 27636181]

44. Rappel P, et al. Subthalamic theta activity: a novel human subcortical biomarker for obsessive compulsive disorder. Transl Psychiatry. 2018; 8:118. [PubMed: 29915200]

45. Wojtecki L, et al. Oscillatory coupling of the subthalamic nucleus in obsessive compulsive disorder. Brain. 2017; 140:e56. [PubMed: 29050377] 
46. Neumann W-J, et al. Pallidal and thalamic neural oscillatory patterns in Tourette syndrome. Ann Neurol. 2018; 84:505-514. [PubMed: 30112767]

47. Servello D, Porta M, Sassi M, Brambilla A, Robertson MM. Deep brain stimulation in 18 patients with severe Gilles de la Tourette syndrome refractory to treatment: the surgery and stimulation. $\mathbf{J}$ Neurol Neurosurg Psychiatry. 2008; 79:136-142. [PubMed: 17846115]

48. Kohl S, et al. Deep brain stimulation for treatment-refractory obsessive compulsive disorder: a systematic review. BMC Psychiatry. 2014; 14:214. [PubMed: 25085317]

49. Figee M, et al. Deep brain stimulation restores frontostriatal network activity in obsessivecompulsive disorder. Nat Neurosci. 2013; 16:386-387. [PubMed: 23434914]

50. Graat I, Figee M, Denys D. The application of deep brain stimulation in the treatment of psychiatric disorders. Int Rev Psychiatry. 2017; 29:178-190. [PubMed: 28523977]

51. Morishita T, Fayad SM, Higuchi MA, Nestor KA, Foote KD. Deep brain stimulation for treatmentresistant depression: systematic review of clinical outcomes. Neurotherapeutics. $2014 ; 11: 475$ 484. [PubMed: 24867326]

52. Riva-Posse $\mathrm{P}$, et al. A connectomic approach for subcallosal cingulate deep brain stimulation surgery: prospective targeting in treatment-resistant depression. Mol Psychiatry. 2018; 23:843849. [PubMed: 28397839]

53. Dougherty DD, et al. A randomized sham-controlled trial of deep brain stimulation of the ventral capsule/ventral striatum for chronic treatment-resistant depression. Biol Psychiatry. 2015; 78:240 248. [PubMed: 25726497]

54. Lozano AM, et al. A phase II study of fornix deep brain stimulation in mild Alzheimer's disease. J Alzheimers Dis. 2016; 54:777-787. [PubMed: 27567810]

55. Sankar T, et al. Deep brain stimulation influences brain structure in Alzheimer's disease. Brain Stimul. 2015; 8:645-654. [PubMed: 25814404]

56. Holtzheimer PE, et al. Subcallosal cingulate deep brain stimulation for treatment-resistant depression: a multisite, randomised, sham-controlled trial. Lancet Psychiatry. 2017; 4:839-849. [PubMed: 28988904]

57. Rehncrona $S$, et al. Long-term efficacy of thalamic deep brain stimulation for tremor: double-blind assessments. Mov Disord. 2003; 18:163-170. [PubMed: 12539209]

58. Goodfellow M, et al. Estimation of brain network ictogenicity predicts outcome from epilepsy surgery. Sci Rep. 2016; 6

59. Lopes MA, et al. An optimal strategy for epilepsy surgery: disruption of the rich-club? PLOS Comput Biol. 2017; 13:e1005637. [PubMed: 28817568]

60. Dayal V, et al. The effect of short pulse width settings on the therapeutic window in subthalamic nucleus deep brain stimulation for Parkinson's disease. J Parkinsons Dis. 2018; 8:273-279. [PubMed: 29843252]

61. Choe C-U, et al. Thalamic short pulse stimulation diminishes adverse effects in essential tremor patients. Neurology. 2018; 91:e704-e713. [PubMed: 30045955]

62. Bouthour W, et al. Short pulse width in subthalamic stimulation in Parkinson's disease: a randomized, double-blind study. Mov Disord. 2018; 33:169-173. [PubMed: 29266392]

63. McIntyre CC, Savasta M, Kerkerian-Le Goff L, Vitek JL. Uncovering the mechanism(s) of action of deep brain stimulation: activation, inhibition, or both. Clin Neurophysiol. 2004; 115:12391248. [PubMed: 15134690]

64. Butson CR, McIntyre CC. Role of electrode design on the volume of tissue activated during deep brain stimulation. J Neural Eng. 2006; 3:1-8. [PubMed: 16510937]

65. McIntyre CC, Mori S, Sherman DL, Thakor NV, Vitek JL. Electric field and stimulating influence generated by deep brain stimulation of the subthalamic nucleus. Clin Neurophysiol. 2004; 115:589-595. [PubMed: 15036055]

66. Butson CR, McIntyre CC. Current steering to control the volume of tissue activated during deep brain stimulation. Brain Stimul. 2008; 1:7-15. [PubMed: 19142235]

67. Steigerwald F, Müller L, Johannes S, Matthies C, Volkmann J. Directional deep brain stimulation of the subthalamic nucleus: a pilot study using a novel neurostimulation device. Mov Disord. 2016; 31:1240-1243. [PubMed: 27241197] 
68. Dembek TA, et al. Directional DBS increases side-effect thresholds-A prospective, double-blind trial. Mov Disord. 2017; 32:1380-1388. [PubMed: 28843009]

69. Pollo C, et al. Directional deep brain stimulation: an intraoperative double-blind pilot study. Brain. 2014; 137:2015-2026. [PubMed: 24844728]

70. Reker P, Dembek TA, Becker J, Visser-Vandewalle V, Timmermann L. Directional deep brain stimulation: a case of avoiding dysarthria with bipolar directional current steering. Parkinsonism Relat Disord. 2016; 31:156-158. [PubMed: 27591075]

71. Fernández-García C, et al. Directional local field potential recordings for symptom-specific optimization of deep brain stimulation. Mov Disord. 2017; 32:626-628. [PubMed: 28339118]

72. Tinkhauser G, et al. Directional local field potentials: a tool to optimize deep brain stimulation. Mov Disord. 2018; 33:159-164. [PubMed: 29150884]

73. Timmermann L, et al. Multiple-source current steering in subthalamic nucleus deep brain stimulation for Parkinson's disease (the VANTAGE study): a non-randomised, prospective, multicentre, open-label study. Lancet Neurol. 2015; 14:693-701. [PubMed: 26027940]

74. Connolly AT, et al. A novel lead design for modulation and sensing of deep brain structures. IEEE Trans Biomed Eng. 2016; 63:148-157. [PubMed: 26529747]

75. Sinclair NC, et al. Subthalamic nucleus deep brain stimulation evokes resonant neural activity. Ann Neurol. 2018; 83:1027-1031. [PubMed: 29727475]

76. Butson CR, Cooper SE, Henderson JM, McIntyre CC. Patient-specific analysis of the volume of tissue activated during deep brain stimulation. Neuroimage. 2007; 34:661-670. [PubMed: 17113789]

77. Frankemolle AMM, et al. Reversing cognitive-motor impairments in Parkinson's disease patients using a computational modelling approach to deep brain stimulation programming. Brain. 2010; 133:746-761. [PubMed: 20061324]

78. Horn A, et al. Connectivity predicts deep brain stimulation outcome in Parkinson disease. Ann Neurol. 2017; 82:67-78. [PubMed: 28586141]

79. Little S, et al. Adaptive deep brain stimulation for Parkinson's disease demonstrates reduced speech side effects compared to conventional stimulation in the acute setting. J Neurol Neurosurg Psychiatry. 2016; 87:1388-1389. [PubMed: 27530809]

80. Herz DM, et al. Mechanisms underlying decision-making as revealed by deep-brain stimulation in patients with Parkinson's disease. Curr Biol. 2018; 28:1169-1178.e6. [PubMed: 29606416]

81. Voges BR, et al. Deep brain stimulation of anterior nucleus thalami disrupts sleep in epilepsy patients. Epilepsia. 2015; 56:e99-e103. [PubMed: 26041007]

82. Swann NC, et al. Adaptive deep brain stimulation for Parkinson's disease using motor cortex sensing. J Neural Eng. 2018; 15

83. Arlotti M, et al. Eight-hours adaptive deep brain stimulation in patients with Parkinson disease. Neurology. 2018; 90:e971-e976. [PubMed: 29444973]

84. Almeida L, et al. Chasing tics in the human brain: development of open, scheduled and closed loop responsive approaches to deep brain stimulation for Tourette syndrome. J Clin Neurol. 2015; 11:122-131. [PubMed: 25851890]

85. Molina R, et al. Report of a patient undergoing chronic responsive deep brain stimulation for Tourette syndrome: proof of concept. J Neurosurg. 2018; 129:308-314. [PubMed: 28960154]

86. Morrell MJ, et al. Responsive cortical stimulation for the treatment of medically intractable partial epilepsy. Neurology. 2011; 77:1295-1304. [PubMed: 21917777]

87. Rouse AG, et al. A chronic generalized bi-directional brain-machine interface. J Neural Eng. 2011; 8

88. Little S, et al. Adaptive deep brain stimulation in advanced Parkinson disease. Ann Neurol. 2013; 74:449-457. [PubMed: 23852650]

89. Little $\mathrm{S}$, et al. Bilateral adaptive deep brain stimulation is effective in Parkinson's disease. J Neurol Neurosurg Psychiatry. 2015

90. Rosa M, et al. Adaptive deep brain stimulation in a freely moving Parkinsonian patient. Mov Disord. 2015; 30:1003-1005. [PubMed: 25999288] 
91. Cagnan H, et al. Stimulating at the right time: phase-specific deep brain stimulation. Brain. 2017; 140:132-145. [PubMed: 28007997]

92. Cagnan, H; Brown, P; Bourget, D; Denison, T. Inertial-based control system concepts for the treatment of movement disorders. 2015 Transducers-2015 18th International Conference on Solid-State Sensors, Actuators and Microsystems (TRANSDUCERS); IEEE; 2015. 70-73.

93. Kühn AA, Kupsch A, Schneider G-H, Brown P. Reduction in subthalamic 8-35 Hz oscillatory activity correlates with clinical improvement in Parkinson's disease. Eur J Neurosci. 2006; 23:1956-1960. [PubMed: 16623853]

94. de Hemptinne C, et al. Exaggerated phase-amplitude coupling in the primary motor cortex in Parkinson disease. Proc Natl Acad Sci USA. 2013; 110:4780-4785. [PubMed: 23471992]

95. de Hemptinne C, et al. Therapeutic deep brain stimulation reduces cortical phase-amplitude coupling in Parkinson's disease. Nat Neurosci. 2015; 18:779-786. [PubMed: 25867121]

96. Neumann W-J, et al. A localized pallidal physiomarker in cervical dystonia. Ann Neurol. 2017; 82:912-924. [PubMed: 29130551]

97. Sani OG, et al. Mood variations decoded from multi-site intracranial human brain activity. Nat Biotechnol. 2018; 36:954-961. [PubMed: 30199076]

98. Herron JA, et al. Chronic electrocorticography for sensing movement intention and closed-loop deep brain stimulation with wearable sensors in an essential tremor patient. J Neurosurg. 2017; 127:580-587. [PubMed: 27858575]

99. Herron, J; Chizeck, HJ. Prototype closed-loop deep brain stimulation systems inspired by Norbert Wiener. 2014 IEEE Conference on Norbert Wiener in the 21st Century (21CW); IEEE; 2014. 6-1.

100. Yamamoto T, et al. On-demand control system for deep brain stimulation for treatment of intention tremor. Neuromodulation. 2013; 16:230-235. [PubMed: 23094990]

101. Basu I, et al. Pathological tremor prediction using surface electromyogram and acceleration: potential use in 'ON-OFF' demand driven deep brain stimulator design. J Neural Eng. 2013; 10

102. Graupe D, Basu I, Tuninetti D, Vannemreddy P, Slavin KV. Adaptively controlling deep brain stimulation in essential tremor patient via surface electromyography. Neurol Res. 2010; 32:899_ 904. [PubMed: 20712926]

103. Tan H, et al. Decoding voluntary movements and postural tremor based on thalamic LFPs for closed-loop stimulation for essential tremor. bioRxiv. 2018; doi: 10.1101/436709

104. Tan H, et al. Decoding gripping force based on local field potentials recorded from subthalamic nucleus in humans. Elife. 2016; 5:e19089. [PubMed: 27855780]

105. Kremen V, et al. Integrating brain implants with local and distributed computing devices: a next generation epilepsy management system. IEEE J Transl Eng Health Med. 2018; 6

106. Tinkhauser G, et al. Beta burst coupling across the motor circuit in Parkinson's disease. Neurobiol Dis. 2018; 117:217-225. [PubMed: 29909050]

107. Cagnan H, Duff EP, Brown P. The relative phases of basal ganglia activities dynamically shape effective connectivity in Parkinson's disease. Brain. 2015; 138:1667-1678. [PubMed: 25888552]

108. Cagnan $\mathrm{H}$, et al. Temporal evolution of beta bursts in the parkinsonian cortico-basal ganglia network. bioRxiv. 2018; doi: 10.1101/458414

109. Rosin B, et al. Closed-loop deep brain stimulation is superior in ameliorating parkinsonism. Neuron. 2011; 72:370-384. [PubMed: 22017994]

110. Tass PA. A model of desynchronizing deep brain stimulation with a demand-controlled coordinated reset of neural subpopulations. Biol Cybern. 2003; 89:81-88. [PubMed: 12905037]

111. Tass PA, et al. Coordinated reset has sustained aftereffects in Parkinsonian monkeys. Ann Neurol. 2012; 72:816-820. [PubMed: 23280797]

112. Adamchic I, et al. Coordinated reset neuromodulation for Parkinson's disease: proof-of-concept study. Mov Disord. 2014; 29:1679-1684. [PubMed: 24976001]

113. Tass PA. Desynchronizing double-pulse phase resetting and application to deep brain stimulation. Biol Cybern. 2001; 85:343-354. [PubMed: 11721989]

114. Holt AB, Wilson D, Shinn M, Moehlis J, Netoff TI. Phasic burst stimulation: a closed-loop approach to tuning deep brain stimulation parameters for Parkinson's disease. PLOS Comput Biol. 2016; 12:e1005011. [PubMed: 27415832] 
115. Wilson D, Moehlis J. Locally optimal extracellular stimulation for chaotic desynchronization of neural populations. J Comput Neurosci. 2014; 37:243-257. [PubMed: 24899243]

116. Ghahremani A, et al. Event-related deep brain stimulation of the subthalamic nucleus affects conflict processing. Ann Neurol. 2018; 84:515-526. [PubMed: 30152889]

117. Patel SR, et al. Intermittent subthalamic nucleus deep brain stimulation induces risk-aversive behavior in human subjects. Elife. 2018; 7:e36460. [PubMed: 30198482]

118. Fischer $\mathrm{P}$, et al. Alternating modulation of subthalamic nucleus beta oscillations during stepping. $\mathrm{J}$ Neurosci. 2018; 38:5111-5121. [PubMed: 29760182]

119. Sharma VD, Sengupta S, Chitnis S, Amara AW. Deep brain stimulation and sleep-wake disturbances in Parkinson disease: a review. Front Neurol. 2018; 9:697. [PubMed: 30210429]

120. Afshar P, et al. A translational platform for prototyping closed-loop neuromodulation systems. Front Neural Circuits. 2013; 6:117. [PubMed: 23346048]

121. Grossman N, et al. Noninvasive deep brain stimulation via temporally interfering electric fields. Cell. 2017; 169:1029-1041.e16. [PubMed: 28575667]

122. Brittain J-S, Probert-Smith P, Aziz TZ, Brown P. Tremor suppression by rhythmic transcranial current stimulation. Curr Biol. 2013; 23:436-440. [PubMed: 23416101]

123. Elias WJ, et al. A pilot study of focused ultrasound thalamotomy for essential tremor. N Engl J Med. 2013; 369:640-648. [PubMed: 23944301]

124. Lipsman N, et al. MR-guided focused ultrasound thalamotomy for essential tremor: a proof-ofconcept study. Lancet Neurol. 2013; 12:462-468. [PubMed: 23523144]

125. Khanna, P; , et al. Enabling closed-loop neurostimulation research with downloadable firmware upgrades. 2015 IEEE Biomedical Circuits and Systems Conference (BioCAS); IEEE; 2015. 1-6.

126. US Food and Drug Administration. [accessed 2 October 2018] Cybersecurity. https:// www.fda.gov/MedicalDevices/DigitalHealth/ucm373213.htm

127. Ritter P, et al. Early performance of a miniaturized leadless cardiac pacemaker: the Micra Transcatheter Pacing Study. Eur Heart J. 2015; 36:2510-2519. [PubMed: 26045305]

128. Oxley TJ, et al. Minimally invasive endovascular stent-electrode array for high-fidelity, chronic recordings of cortical neural activity. Nat Biotechnol. 2016; 34:320-327. [PubMed: 26854476]

129. Wiegert JS, Mahn M, Prigge M, Printz Y, Yizhar O. Silencing neurons: tools, applications, and experimental constraints. Neuron. 2017; 95:504-529. [PubMed: 28772120]

130. Dunbar CE, et al. Gene therapy comes of age. Science. 2018; 359

131. Williams JC, Denison T. From optogenetic technologies to neuromodulation therapies. Sci Transl Med. 2013; 5:177ps6.

132. Legon W, Bansal P, Tyshynsky R, Ai L, Mueller JK. Transcranial focused ultrasound neuromodulation of the human primary motor cortex. Sci Rep. 2018; 8

133. Legon W, Ai L, Bansal P, Mueller JK. Neuromodulation with single-element transcranial focused ultrasound in human thalamus. Hum Brain Mapp. 2018; 39:1995-2006. [PubMed: 29380485]

134. Ai L, Bansal P, Mueller JK, Legon W. Effects of transcranial focused ultrasound on human primary motor cortex using 7T fMRI: a pilot study. BMC Neurosci. 2018; 19:56. [PubMed: 30217150]

135. Bertrand A, et al. Beamforming approaches for untethered, ultrasonic neural dust motes for cortical recording: a simulation study. Conf Proc Annu Int Conf IEEE Eng Med Biol Soc. 2014; 2014:2625-2628.

136. Neely RM, Piech DK, Santacruz SR, Maharbiz MM, Carmena JM. Recent advances in neural dust: towards a neural interface platform. Curr Opin Neurobiol. 2018; 50:64-71. [PubMed: 29331738]

137. Seo D, et al. Wireless recording in the peripheral nervous system with ultrasonic neural dust. Neuron. 2016; 91:529-539. [PubMed: 27497221]

138. Jermakowicz WJ, et al. Laser thermal ablation for mesiotemporal epilepsy: analysis of ablation volumes and trajectories. Epilepsia. 2017; 58:801-810. [PubMed: 28244590]

139. McClelland S III, Jaboin JJ. Treatment of the ventral intermediate nucleus for medically refractory tremor: a cost-analysis of stereotactic radiosurgery versus deep brain stimulation. Radiother Oncol. 2017; 125:136-139. [PubMed: 28818305] 
140. Harris M, et al. MRI-guided laser interstitial thermal thalamotomy for medically intractable tremor disorders. Mov Disord. 2019; 34:124-129. [PubMed: 30452785]

141. Hawkes CH, Del Tredici K, Braak H. Parkinson's disease: a dual-hit hypothesis. Neuropathol Appl Neurobiol. 2007; 33:599-614. [PubMed: 17961138]

142. Svensson E, et al. Vagotomy and subsequent risk of Parkinson's disease. Ann Neurol. 2015; 78:522-529. [PubMed: 26031848]

143. McIntyre CC, Hahn PJ. Network perspectives on the mechanisms of deep brain stimulation. Neurobiol Dis. 2010; 38:329-337. [PubMed: 19804831]

144. Contarino MF, et al. Directional steering: a novel approach to deep brain stimulation. Neurology. 2014; 83:1163-1169. [PubMed: 25150285]

145. Valentín A, et al. Deep brain stimulation of the centromedian thalamic nucleus for the treatment of generalized and frontal epilepsies. Epilepsia. 2013; 54:1823-1833. [PubMed: 24032641]

146. Heck CN, et al. Two-year seizure reduction in adults with medically intractable partial onset epilepsy treated with responsive neurostimulation: final results of the RNS System Pivotal trial. Epilepsia. 2014; 55:432-441. [PubMed: 24621228]

147. Bittar RG, et al. Deep brain stimulation for pain relief: a meta-analysis. J Clin Neurosci. 2005; 12:515-519. [PubMed: 15993077]

148. Schultz DM, et al. Sensor-driven position-adaptive spinal cord stimulation for chronic pain. Pain Physician. 2012; 15:1-12. [PubMed: 22270733]

149. Schade CM, Schultz DM, Tamayo N, Iyer S, Panken E. Automatic adaptation of neurostimulation therapy in response to changes in patient position: results of the Posture Responsive Spinal Cord Stimulation (PRS) Research Study. Pain Physician. 2011; 14:407-417. [PubMed: 21927044]

150. Russo M, et al. Effective relief of pain and associated symptoms with closed-loop spinal cord stimulation system: preliminary results of the Avalon Study. Neuromodulation. 2018; 21:38-47. [PubMed: 28922517]

151. Cameron T, Alo KM. Effects of posture on stimulation parameters in spinal cord stimulation. Neuromodulation. 1998; 1:177-183. [PubMed: 22151029]

152. Olin JC, Kidd DH, North RB. Postural changes in spinal cord stimulation perceptual thresholds. Neuromodulation. 1998; 1:171-175. [PubMed: 22151028]

153. Lesser RP, et al. Brief bursts of pulse stimulation terminate afterdischarges caused by cortical stimulation. Neurology. 1999; 53:2073-2081. [PubMed: 10599784]

154. Sun FT, Morrell MJ. Closed-loop neurostimulation: the clinical experience. Neurotherapeutics. 2014; 11:553-563. [PubMed: 24850309]

155. Gotman J. Automatic recognition of epileptic seizures in the EEG. Electroencephalogr Clin Neurophysiol. 1982; 54:530-540. [PubMed: 6181976]

156. Esteller, R; Echauz, J; Tcheng, T; Litt, B; Pless, B. Line length: an efficient feature for seizure onset detection. 2001 Conference Proceedings of the 23rd Annual International Conference of the IEEE Engineering in Medicine and Biology Society; IEEE; 2001. 1707-1710. Vol. 2

157. Litt, B; , et al. Evolution of accumulated energy predicts seizures in mesial temporal lobe epilepsy. Proceedings of the First Joint BMES/EMBS Conference. 1999 IEEE Engineering in Medicine and Biology 21st Annual Conference and the 1999 Annual Fall Meeting of the Biomedical Engineering Society; 1999. 440

158. Maling N, Lempka SF, Blumenfeld Z, Bronte-Stewart H, McIntyre CC. Biophysical basis of subthalamic local field potentials recorded from deep brain stimulation electrodes. $\mathrm{J}$ Neurophysiol. 2018; 120:1932-1944. [PubMed: 30020838] 


\section{Box 1}

\section{FDA-approved closed-loop stimulation strategies}

Chronic use of closed-loop electrical stimulation has been shown to be effective and safe for the management of pain and epilepsy.

\section{Closed-loop spinal cord stimulation for pain.}

Applications in this indication have been motivated by the observation that effective stimulation parameters varied according to patients' posture ${ }^{151,152}$. In the Medtronic RestoreSensor system, stimulation parameters are adaptively adjusted according to patients' posture as measured via a triaxial accelerometer integrated into the implanted stimulator. The mapping between effective stimulation settings and patients' posture is determined in an open-loop fashion. This mapping is then used to automatically adjust stimulation according to changes in patients' posture to ensure that stimulation efficacy is retained throughout the day ${ }^{148,149}$. By contrast, in the Saluda Evoke SCS system, compound action potentials evoked by spinal cord stimulation are sensed and interpreted to achieve continuous stimulation efficacy. The preferred evoked action potential amplitude is determined in a patient-specific manner and assessed continuously following each stimulation pulse. Stimulation intensity is then adaptively either increased or reduced to sustain effective recruitment of dorsal column fibers ${ }^{150}$.

\section{Closed-loop stimulation for epilepsy.}

This area has been motivated by the observation that brief electrical stimulation is effective in terminating afterdischarges observed as a result of cortical stimulation ${ }^{153}$. In the RNS Neurostimulator system, cortical stimulation is delivered to the seizure focus when epileptic electrocorticographic activity is detected. Several options are provided for detecting epileptic electrocorticographic activity. These algorithms rely on detection of (i) rhythmic electrocorticographic activity in a specific frequency band, (ii) certain changes in the instantaneous electrocorticographic activity with respect to neural activity observed over a longer period of time, and (iii) the overall increase in electrocorticographic signal power ${ }^{154-157}$. Critically, it has been suggested that the total duration of stimulation could be reduced to fewer than $5 \mathrm{~min}$ from $24 \mathrm{~h}$ when the stimulation is delivered in a closedloop fashion ${ }^{153}$. 

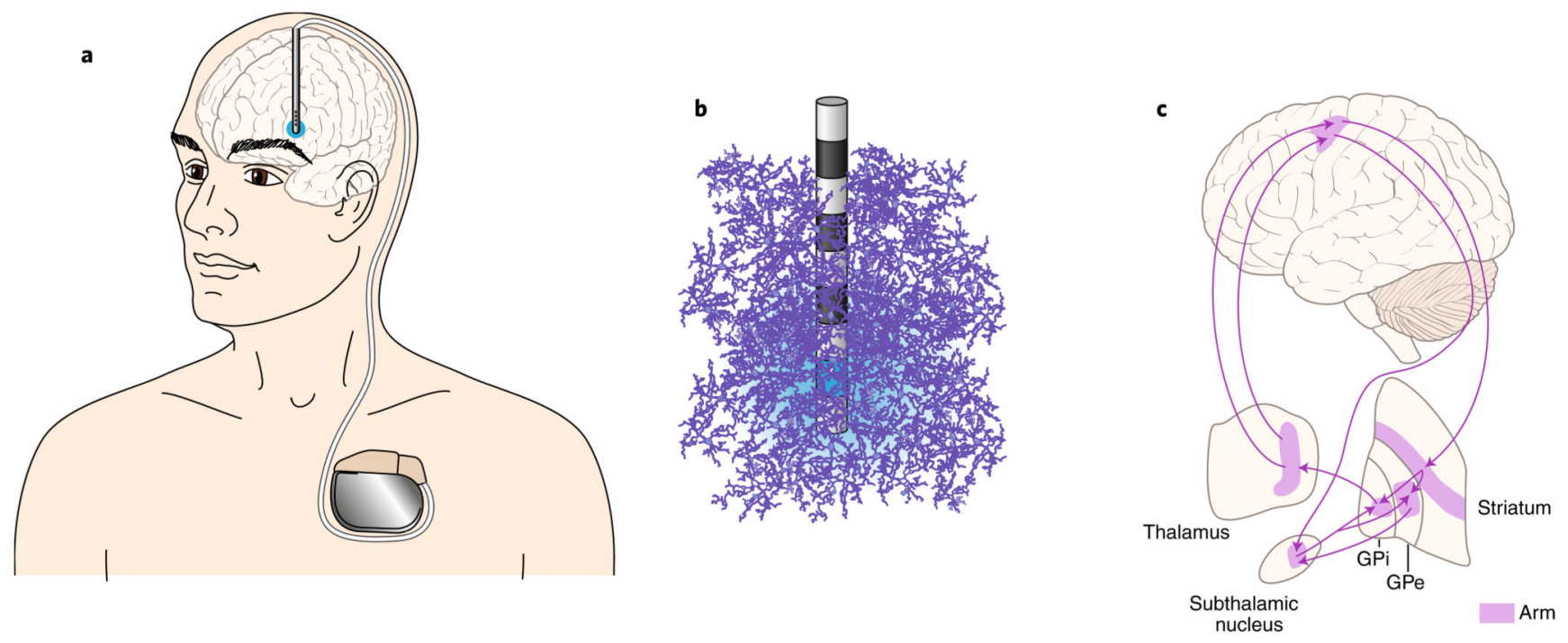

Fig. 1. Deep brain stimulation.

a, The electrodes and pulse generators are permanently implanted, self-contained systems. Electrodes can be implanted in one or both hemispheres of the brain, depending on the laterality of the symptoms. The electrode(s) implanted in the brain are connected to the pulse generator implanted in the chest. b. Traditional DBS electrodes consisted of four contacts (black cylinders), where typically a single contact was used to deliver stimulation. The most common surgical target for the treatment of Parkinson's disease is the subthalamic nucleus, which contains $\sim 250,000$ neurons, depicted in blue, and is much denser in reality than shown here. (Adapted with permission from ref. ${ }^{158}$.) c, DBS enables wide-scale network modulation of the basal ganglia and cortex. This is because these structures are coupled into loops. There are many such overlapping loops, but here, for schematic purposes, a loop controlling the arm is illustrated. GPe, globus pallidus externa; GPi, globus pallidus interna. (Reprinted from ref. ${ }^{143}$, Neurobiol. Dis. 38, C. C. McIntyre \& P. J. Hahn, Network perspectives on the mechanisms of deep brain stimulation, 329-337, copyright 2010, with permission from Elsevier.). 
a

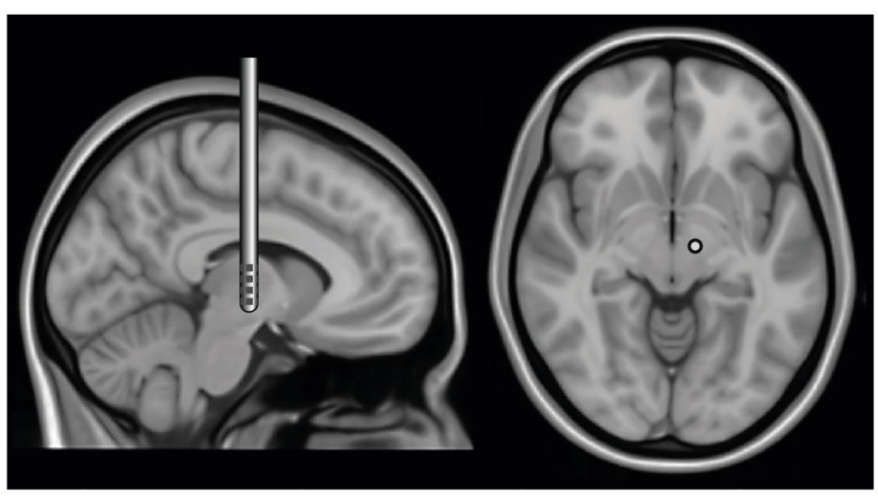

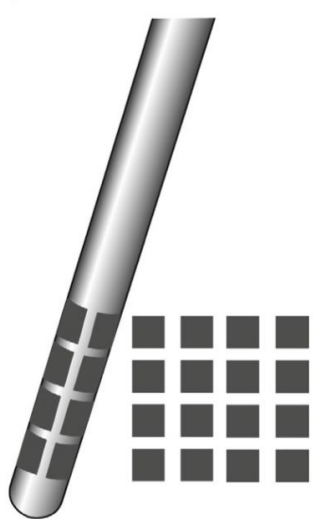

C

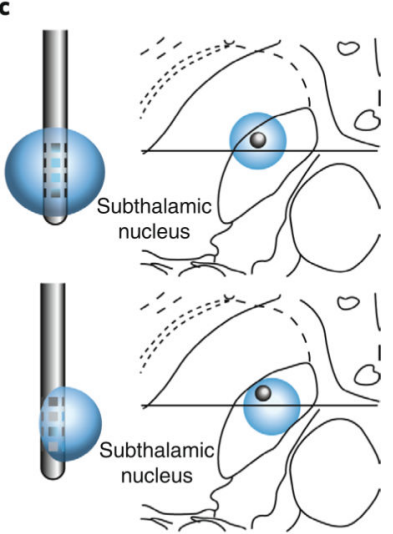

Fig. 2. Field steering.

a, Schematic DBS electrode shown on magnetic resonance imaging scans targeting the subthalamic nucleus. Perioperative imaging is essential and intraoperative imaging desirable in the accurate placement of electrodes. b, Prototype research electrodes have been developed with higher densities of smaller contacts. c, These are designed with the intention of providing finer control of the electric field (blue volume). The top panel illustrates the spherical field predominating when a complete ring of contacts is activated to mimic the field derived with conventional DBS. On the right, the electrode and electric field are superimposed on a brain atlas. The electrode is in the target, the subthalamic nucleus, but the electric field extends outside of this, risking side effects. The lower panel illustrates the shaping of the electrical field that is possible when a subset of contacts is simultaneously activated. Now the field is limited to the subthalamic nucleus. (Adapted from ref. ${ }^{144}$; atlas image adapted with permission from G. Schaltenbrand \& W. Wahren, Atlas for Stereotaxy of the Human Brain 2nd edn, Thieme, 1977.). 
a

Open-loop stimulation

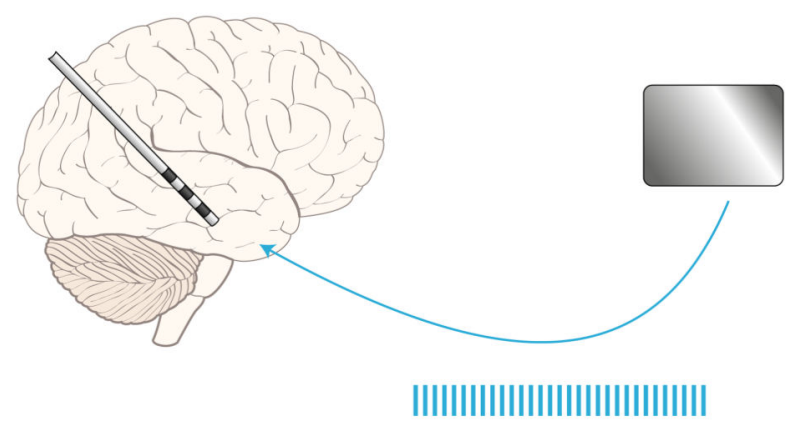

C Closed-loop stimulation

Sensing using cortical electrodes and stimulating via the depth electrodes

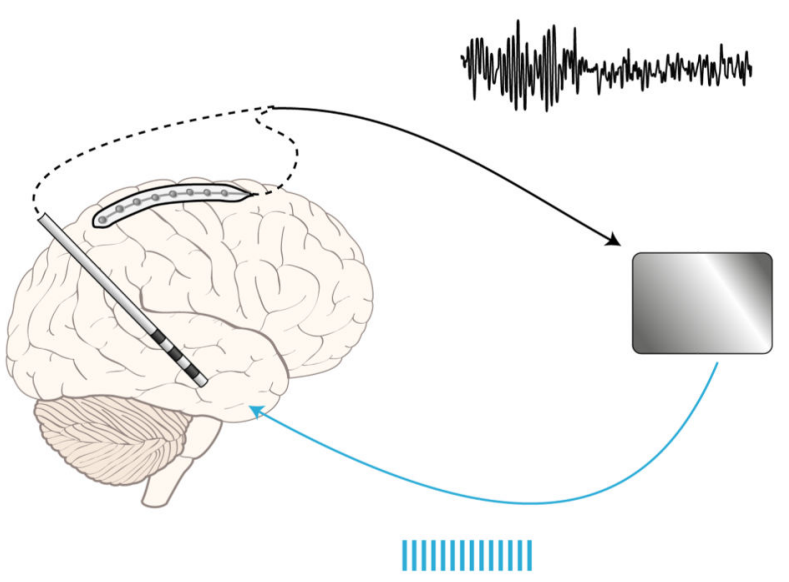

b

Closed-loop stimulation

Sensing and stimulating via the same electrode

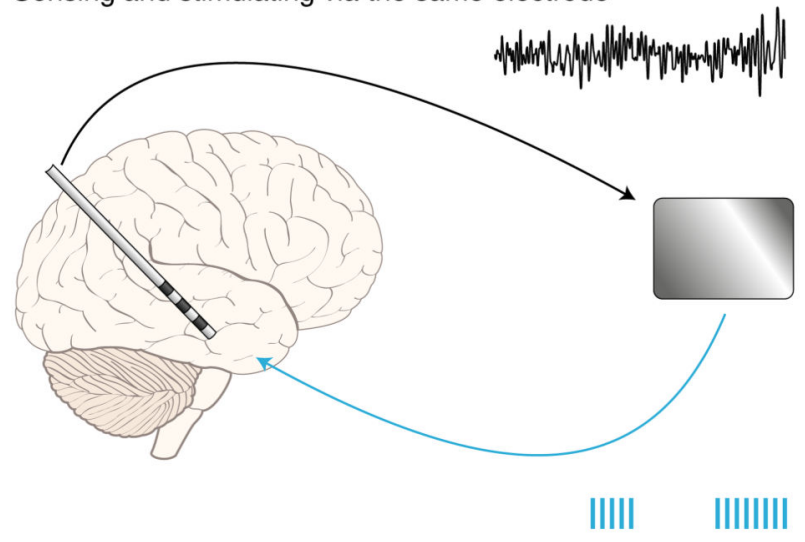

d Closed-loop stimulation

Sensing using peripheral sensors and stimulating via the depth electrodes

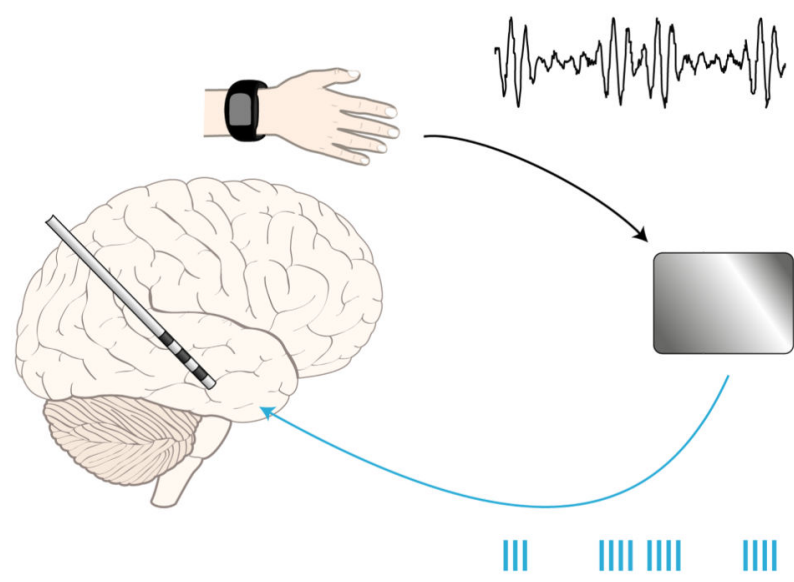

Fig. 3. A comparison of different stimulation strategies.

a comparison of different stimulation strategies. a, Stimulation timing and parameters are not automatically adjusted according to a disease biomarker, although the clinician will finetune stimulation during follow-up visits (usually twice a year). b, Local field potentials sensed using depth electrodes are continuously used to automatically determine stimulation timing or intensity. Stimulation is delivered via the same depth electrodes. c, Cortical signals sensed using an electrocorticography array are continuously used to automatically determine stimulation timing or intensity. Stimulation is delivered across the depth electrodes, creating a spatial separation between sensing and stimulation sites. d, Peripheral signals obtained from noninvasive measurement devices, such accelerometers and/or electromyography, are used to automatically determine stimulation timing or intensity. As in c, this allows a separation between sensing and stimulation sites and therefore minimizes the impact of stimulation artifacts. The gray box represents a computing device and could be an implantable pulse generator, a computer or cloud-based computing. The computing device is 
used to process signals and extract features such as the intensity of neural activity in a certain frequency band or phase-amplitude coupling to control stimulation timing and parameters. 
Table 1

A summary of established and experimental DBS targets

\begin{tabular}{|c|c|c|c|}
\hline Disorder & Target brain region & DBS approach & Refs. \\
\hline \multirow[t]{2}{*}{ Parkinson's disease } & \multirow{2}{*}{$\begin{array}{l}\text { Subthalamic nucleus } \\
\text { Globus pallidus (internal) } \\
\text { Ventrolateral thalamus } \\
\text { Pedunculopontine nucleus }\end{array}$} & Continuous high-frequency stimulation & $2-4,13,14$ \\
\hline & & Closed-loop DBS & $79,82,88-90$ \\
\hline \multirow[t]{2}{*}{ Essential tremor } & \multirow[t]{2}{*}{ Ventrolateral thalamus } & Continuous high-frequency stimulation & $5,6,57$ \\
\hline & & Closed-loop DBS & $91,98,100,101$ \\
\hline Dystonia & Globus pallidus (internal) & Continuous high-frequency stimulation & $7-10$ \\
\hline \multirow[t]{3}{*}{ Epilepsy } & \multirow{3}{*}{$\begin{array}{l}\text { Centromedian thalamus } \\
\text { Anterior thalamic nucleus } \\
\text { Seizure foci }\end{array}$} & Intermittent $20-\mathrm{Hz}$ stimulation & 43 \\
\hline & & $\begin{array}{l}\text { High-frequency stimulation (continuous or } \\
\text { cyclic mode) }\end{array}$ & 81,145 \\
\hline & & Closed-loop DBS & 86,146 \\
\hline \multirow[t]{2}{*}{ Pain } & \multirow{2}{*}{$\begin{array}{l}\text { Spinal cord } \\
\text { Periventricular or periaqueductal gray matter } \\
\text { Sensory thalamus } \\
\text { Internal capsule }\end{array}$} & Continuous low- or high-frequency stimulation & 147 \\
\hline & & Closed-loop stimulation & $148-150$ \\
\hline $\begin{array}{l}\text { Obsessive compulsive } \\
\text { disorder }\end{array}$ & $\begin{array}{l}\text { Subthalamic nucleus } \\
\text { Nucleus accumbens } \\
\text { Anterior limb of the internal capsule } \\
\text { Ventral capsule or ventral striatum } \\
\text { Inferior thalamic peduncle }\end{array}$ & Continuous high-frequency stimulation & $44,45,48,49$ \\
\hline Major depression & $\begin{array}{l}\text { Subcallosal cingulate } \\
\text { Ventral capsule or ventral striatum }\end{array}$ & Continuous high-frequency stimulation & $51-53,56$ \\
\hline \multirow[t]{2}{*}{ Tourette syndrome } & \multirow{2}{*}{$\begin{array}{l}\text { Globus pallidus (internal) } \\
\text { Centromedian-parafascicular }\end{array}$} & Continuous high-frequency stimulation & 46,47 \\
\hline & & Closed-loop deep brain stimulation & 85 \\
\hline Alzheimer's disease & Fornix & Continuous high-frequency stimulation & 54,55 \\
\hline
\end{tabular}

